INTERNATIONAL DESIGN CONFERENCE - DESIGN 2018

https://doi.org/10.21278/idc.2018.0420

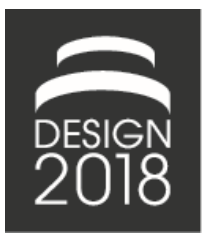

\title{
COLLABORATIVE DESIGN: LINKING METHODS, COMMUNICATION TOOLS AND COMPETENCIES TO PROCESSES
}

\author{
A.-K. Bavendiek, T. Huth, D. Inkermann, H. Paulsen, T. Vietor and S. Kauffeld
}

\begin{abstract}
Today's design processes involve various persons and disciplines. Process participants are often distributed in different sites and might have diverse cultures. Thus, collaborations are often confusing due to the different parties. This paper uses a model considering 3 layers of collaborations: process, methods \& tools and competencies \& qualification. Each layer is modelled or supported by existing tools but a holistic modelling approach to represent relations between the 3 layers is missing. This research work proposes a modelling approach showing design processes on all 3 layers using BPMN.
\end{abstract}

Keywords: process modelling, collaborative design, design methods, competencies

\section{Introduction}

The development of a product is usually performed by interdisciplinary teams. Thus, a collaboration of experts from various disciplines is required to bring together the diverse expertise needed to develop today's products. These products are characterized by a combination of mechanics, electronic, software and eventually a service as well to fulfil their designated purpose. The involvement of diverse disciplines and expertise demand well-working structures for collaborations to succeed with the development task.

Furthermore, the distribution of the experts is no longer bound to one enterprise and one site; it can be locally spread over regions, nations and also over the world. The local distribution brings additional challenges to the collaborations, like cultural differences, language problems and technical problems, e.g., for exchanging information. In addition, new competencies are required to cope with these challenges like intercultural awareness, language skills or confidence in the results of other partners from the collaboration.

Considering the increasing digitalisation of the working environment, it can be assumed that time spent in collaborations, primarily for coordination and communication, will further increase or at least stagnate at a high level as it is today. The assumption is based on findings of Schleidt and Eigner (2010), who identified an increasing amount of time spent on communication and coordination during the years 2000 to 2006. Due to the importance of collaborative design, various authors deal with research on collaborations with diverse foci, e.g., Robin et al. (2007), Törlind and Larsson (2002) or Talas et al. (2017). A theoretical explanation model for describing influences and interdependencies within collaborations was presented by Bavendiek et al. (2017). This previous work will be the basis for the contribution at hand. Shortcomings for the practical application will be highlighted and extensions for the use in practice will be proposed.

\subsection{Views on collaborative design}

First, the field of research on collaborations will be clarified. Collaborative design is seen as the communication, coordination and also collaboration of a team that pursues the goal to fulfil an engineering 
design task. Different disciplines as well as local distributed sites may be involved. Thereby, a degree of virtuality will be used to describe collaborations. This degree is mainly depending on the composition of the collaboration team. The more virtual communication, coordination and collaboration are required due to the collaboration characteristics, the higher the degree of virtuality. This takes into account that a team working together at one site might communicate mainly virtually (via e-mail or telephone) whereas a locally distributed team might use frequently face-to-face meetings. As collaboration characteristics, those presented by Anderl et al. (1999) will be the reference. To those characteristics belong amongst others time, location, language, size of company and distribution of tasks.

In a more general way, collaborative design can be considered from different views. These views are according to Bavendiek et al. (2016a) the process, technical-methodical and personal view. It is important to always have all views in mind, when trying to support collaborations. Actually, seldom multiple points like technological, human or expertise are supported by one approach in collaborative design (Wallace et al., 2001). The existing research efforts in this field were mainly disappointing (Robin et al., 2007). Thus, the PMC model (see Figure 1) presented a holistic view on collaborative design. The model displays collaborations on three layers: the process layer, methods $\&$ tools layer, and the competencies \& qualification layer (Bavendiek et al., 2017). These layers correspond to the three views introduced above. The process layer describes elements like participants or stakeholders, design activities and information flows. The methods \& tools layer includes, additionally, all kinds of communication, coordination and collaboration technologies (e.g., video conferencing). The third layer contains information on required expertise and available competencies. All layers are connected to the design task, which influences the elements on the layers significantly and sets the focus for instance for the activities. Moreover, the layers are not independent; there are interactions between them. (Bavendiek et al., 2017).

The aim of the PMC model is to describe current situations in collaborative design and, thus, identify so-called hot spots that have to be supported, like reducing redundant work. These hot spots can be identified on each layer focussing for instance on the professional expertise, the methods used to support design activities or information flows between different sites.

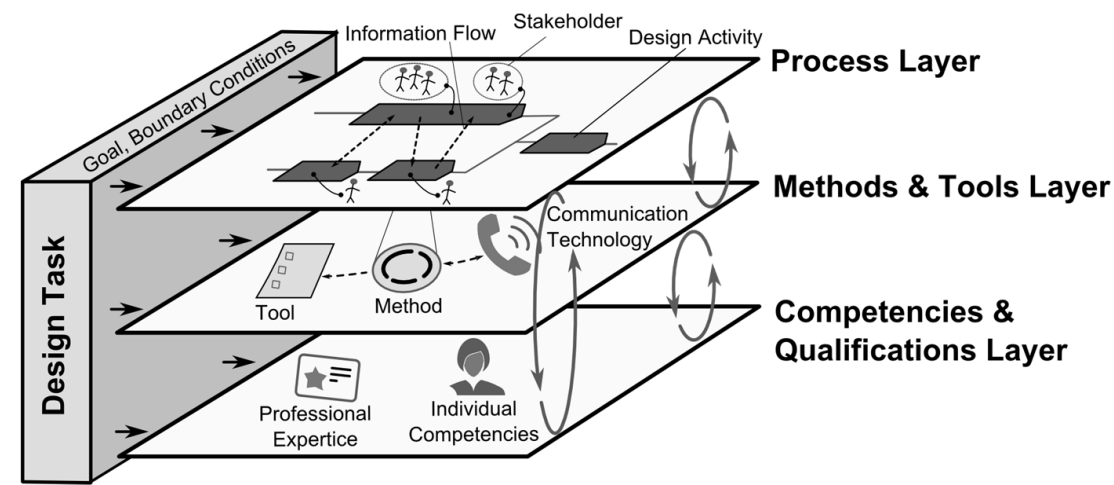

Figure 1. PMC model to describe collaborative design on different layers (Bavendiek et al., 2017)

\subsection{Problem statement}

The introduced PMC model can help to analyse collaborative design situations holistically as it considers different views. It is not intended to support collaborations directly. The main purposes are observation and training. The application in practice has shown that the model seems to be too abstract for practitioners. It serves for explications; a direct illustration of interdependencies is not destined and possible. A common basis to describe all interdependencies of (complex) collaborative situations is currently missing. There exist various tools and models for each layer separately or for the combination of two layers (see Section 2). A holistic approach linking all three views was not yet presented. Bavendiek et al. (2016a) demonstrate a combination of technical-methodological view and personal view. The process view is only marginally considered. 
For industry applications, a more concrete approach is required to increase the value of a support. The aim of this research is, thus, to link all three layers together in one modelling approach that is simple to apply and understand. The resulting model shall then be used for (1) current state analysis of existing collaborations. Bottle necks and critical situations can be identified from the model. The model assists (2) the suggestion of future processes, which are needed, e.g., due to new technologies that are introduced or due to outsourcing of development departments.

To achieve the stated aim, this contribution tries to answer the following research questions:

1. How do existing approaches support collaborative design on the process, methods \& tools and competencies \& qualification layer?

2. How can the three above mentioned layers of collaborative design be linked within one modelling approach?

To address the questions set up, Section 2 focusses on existing approaches to support or to model elements on the process, methods \& tools and competencies \& qualification layer. The third section will introduce a modelling approach that allows the illustration of interdependencies of all three layers in one resulting model. Section 4 presents the application with an industry partner to demonstrate the benefits. The approach will be critically discussed and a conclusion is drawn in the last section.

\section{Basics on support and models for collaborative design}

This section aims at answering the first research question by giving an overview of current approaches to support collaborative design or to model the elements on each layer or across layers. Each layer will be examined individually section by section. Thereby, the approaches are assigned to the layers according to their main focus. Section 2.4 reviews approaches that combine multiple layers.

\subsection{Process layer}

The process layer represents a flow-oriented view upon the collaborative design. There are many approaches to model product data and/or processes in engineering design. Other authors deal with general knowledge representation using various modelling approaches. A great overview on these modelling approaches is given by Eckert et al. (2017). In this contribution, the aim of the process layer is to represent the logical order of process activities executed by the process participants supplemented by the used data or models and information flows. One possible and well-established solution is the existing representations for business processes (BP). Herein, business objects, also referred to as business artefacts, are utilized to represent associated information needed or provided for or by activities during the process, e.g., bill of materials or requirements specification.

Modelling of business processes is normally conducted as part of business process management (BPM). The main goal of BPM is to monitor, iteratively describe, improve and implement a business's processes (Ferguson and Stockton, 2006). BPs are normally described as some sort of model. There are many different sorts of process models and even more different modelling tools available. More generally, during process modelling, business process models are generated that formally describe the BPs. Within the models, the processes can also be described on different levels of detail, like a superordinate strategic view on the overall process or a very detailed operational view on single tasks (Wynn and Clarkson, 2017). To create these models, i.e., graphical methods are used. Graphical methods use diagrams for the documentation of the processes, on which the process is modelled in accordance with a special syntax and semantics. In the graphic methods, data and control flow oriented as well as object oriented approaches can be distinguished.

According to Ferguson and Stockton (2006) there is a trend to a more formal modelling of BP. Formal modelling has at least one major benefit for everybody dealing with BP models: a precise notation. Formal (graphical) modelling languages like the Business Process Model and Notation (BPMN) (Object Management Group, 2011) provide a standardized syntax and semantic, which are implemented by many different tools. The BPMN, though, is a notation mainly for representing processes and their information flows graphically. It is mainly used for analysing purposes (Wohed et al., 2006).

According to Wynn and Clarkson (2017), basically four types of process models can be distinguished, which can be used for different purposes. The four types are procedural, analytical, and abstract models, 
as well as models from business management / operations research. Procedural models represent best practices, such as the VDI 2206 (Verein Deutscher Ingenieure, 2004). Analytical models provide situation-specific views of specific processes. Abstract models represent theoretical process approaches and basic concepts. Wynn and Clarkson (2017) assign the integrated product engineering model (Albers et al., 2016) to this area, for example. On the other hand, models from the field of corporate management / operations research use analytical methods to draw inferences from the processes (Wynn and Clarkson, 2017). In our work, we focus on procedural and analytical models that allow the representation of development tasks on different levels (strategic and operative).

Wohed et al. (2006) identified several main elements represented in a formal process model. The main elements to be represented on the process layer for collaborative design processes are:

- participants/stakeholders involved in the design process, for instance team members, departments or whole companies

- information flows in terms of connections between different activities of participants with specification of direction of the flow

- design activities as several procedures executed within the overall design process

An exemplary design activity is the integration of sub models within a simulation model for collision control. Furthermore, preconditions to execute design activities (sequence of activities) as well as parallelism of different activities are represented.

\subsection{Methods \& tools layer}

The methods \& tools layer contains not only methods and tools that support the design process but also technologies supporting the different aspects. The provision of methods and tools assisting for instance the ideation or evaluation of solutions is only one part of support on this layer. Various authors suggested method collections (e.g., Cross, 2007; Lindemann, 2009), method portals (e.g., SPP GmbH, 2004; TIM, 2013; Bavendiek et al., 2016b) or mobile applications like Albers et al. (2015) suggest to support the designer when searching for methodical assistance. Most of these method provision approaches map the methods to design activities or phases of the process, like it is done in some "elementary methods" approaches (Zanker, 1999; Zier and Birkhofer, 2013). So, a first linkage to the process layer is given.

Besides the methods, technologies that enable the collaboration are even more important when designing in locally distributed teams. According to Grieb (2008), these technologies (or media) can be distinguished in traditional (phone, fax, postage or face-to-face meetings), computer-based technologies and those based on virtual reality (VR). Grieb and Lindemann (2005) conducted a survey in industry to identify often-used media in regard to different (product) models. They list strengths and weaknesses for the most important media respectively communication technologies.

A wide field of research focusses on the computer-supported collaborative work (CSCW). Besides collaborating, the communication and coordination in teams are of interest in this field (Robin et al., 2007). As both aspects of daily work rise (see Introduction), many authors address support on these aspects. Robin et al. (2007) focus on the exchange of knowledge and information within collaborations presenting the IPPOP software as a support tool. This software tool uses the GRAI modelling approach earlier presented by Girard and Merlo (2003). Pol et al. (2008) investigate on the implementation of coordination mechanisms in PLM systems, whereas Yesilbas et al. (2006) use UML diagrams to demonstrate conflict management support for collaborations.

Focussing more on the communication aspects, another author proposes a support tool that helps identifying adequate communication technologies based on the characteristics of the information to share (Gaul, 2001). Combining the communication with diagrams originating in the development process like product structures, specifications and design rationales, for visualisation purpose to simplify the traceability of documents is a further approach presented by Martinec and Pavkovic (2014).

One of the major problems of communication of locally distributed teams are missing informal communication possibilities. Informal communication is all kind of "informal, accidental, spontaneous communication that characterizes everyday work" (Törlind and Larsson, 2002). It is considered as very important for successful communication within organisations. Thus, Törlind and Larsson (2002) developed an informal communication tool to enable chat and other informal communication in 
distributed working teams. Another approach belonging to the VR technologies is the creation of a virtual meeting environment that allows the participants to interact with the complete upper part of the body with others like it is proposed by Arthur Technologies (2017).

\subsection{Competencies \& qualification layer}

In today's development, processes are mainly teams of designers or engineers involved, so, the importance of personal aspects rises. In collaborations, which include per definition multiple persons, the personal view and, thus, the competencies \& qualification layer may become even more important due to the increasing complexity of the social system. Competencies comprise knowledge, skills, abilities and other characteristics that help to better deal with job demands, e.g., (Mansfield, 1996; Campion et al., 2011; Kauffeld and Paulsen, 2018). Competencies are reflected in observable behaviour in specific social situations and closely linked to performance outcomes (Schleidt, 2009; Campion et al., 2011; Kauffeld and Paulsen, 2018). Competencies are independent on the way of learning. Competencies can be developed through formal off-the-job or informal learning on the job (Kauffeld and Paulsen, 2018). In contrast, qualifications are linked to formal learning, depend on learning input and often comprise a test and certification. Qualification can, but do not necessary help persons to deal with actual job demands. However, qualifications are often important for legal issues. For example, specific actions can require certificates according to laws, professional standards or set of regulations.

Focussing on competencies within collaborations, the competencies required for a successful teamwork depend on the degree of virtuality of a team (Shin, 2004; Schleidt and Eigner, 2010; Krumm et al., 2016; Schulze et al., 2017; Schulze and Krumm, 2017). A team locally situated close to each other, for instance, can have a high degree of virtuality when the team members usually communicate virtually, although the local distribution is low. Competency models are a way to describe and arrange needed competencies for organizations (Sanchez and Levine, 2009; Campion et al., 2011). These can be added by diagnosis tools that enable the consideration of the competency development of single team members, a team or an organization. An example for this kind of a support tool is the Kompetenz-Navi (competency navigator), a web-based and adaptive tool for competency assessment, e.g., (Kortsch et al., 2018), or the VICO (virtual qualification coach) proposed by Auffermann et al. (2007). The Kompetenz-Navi supports HR managers as well as supervisors or project leaders to economically assess competencies of their staff, detect gaps and potentials for personal and team development. The VICO tool considers 14 clusters of special organizational competencies in virtual collaborations. VICO is not especially intended to be used for engineering design collaborations. This transfer to the engineering domain is done by Schleidt (2009) who presents the House of Engineering Competencies. This House correlates cross-enterprise working conditions to relevant competencies. A similar approach is represented in the PEGASE tool, which considers knowledge, activity, autonomy and quality of different persons within an enterprise (Rose et al., 2009). The focus of this research lies on the collaboration of different engineering domains.

\subsection{Combined approaches}

As combined approaches, those are presented in the following that address not only one of the PMC model's layers but at least two. Some of the support tools or modelling approaches on the process and methods \& tools layer cannot be clearly assigned to just one layer although it was done in the previous sections. The main purpose of the presented approaches as described by the authors is chosen for the assignment. The overview presented by Eckert et al. (2017) demonstrates the close connection of processes and methods \& tools, too. Many modelling approaches consider information or knowledge in regard to design activities or process steps, e.g., (Girard and Merlo, 2003; Robin et al., 2007). The linkage is reasonable as tools and technologies serve to transfer information.

Although some authors stress the importance to consider the design team or the designer in the process (e.g., Rose et al., 2009), only a few research works deal with the consideration of the interrelations of competencies and methods \& tools or of competencies and processes. The latter interrelation is investigated for instance by Martinec et al. (2017) who use videotaping to later code the communication within meetings. The single communication elements are then assigned to activities. In this approach analysis, synthesis and evaluation activities are distinguished. As the coding is based on meetings, a complete match to the process layer is not available. There were earlier approaches also using 
videotaping and coding schemes for analysing different aspects of team meetings (e.g., Stempfle and Badke-Schaub, 2002; Gero and Kannengiesser, 2004). One approach already investigated on the impact of method use in team meetings. In this work, the authors found a higher satisfaction of the team members when applying methods (like Morphological Scheme or Brainwriting) in meetings compared to no method usage (Bavendiek et al., 2015). A dependency between competencies and critical situation (as part of the process layer) is presented by Badke-Schaub and Frankenberger (2004). They discuss the importance of different competencies in various critical situations in engineering design processes.

The interrelation of competencies and methods is rarely addressed. Mapping required competencies as well as characteristics in a collaboration to methods and tools using a correlation matrix is one possible approach, which was proposed in earlier work (Bavendiek et al., 2016a).

To summarize the considered approaches to support and model engineering design collaborations, it can be stated that there are few authors dealing with more than one of the layers from the PMC model (process, methods \& tools and competencies \& qualification). For linking the three layers consequently, another approach is needed to fully represent the interrelations between the layers and, thus, understand better collaborations and how they can be supported.

\section{Modelling approach for collaborative design}

After reviewing some of the existing approaches dealing with support and models for collaborative design, the second research question on how to link the three layers (process, methods \& tools and competencies \& qualification) will be addressed in the following. Therefore, an approach for generating a model combining the three layers is presented. For creating the model, a combination of different modelling languages is used. We take advantage of the fact that the used modelling solution offers support for a wide range of modelling languages and implements these based on UML. Because of that, the different modelling languages can be used together in one model. The processes as a major part of the model are modelled by using BPMN elements as standardized by the OMG (Object Management Group, 2011). Thus, the starting point of the modelling approach is the process layer. In the following, models on this layer will be explained with the aid of an example presented in Figure 2 showing an exemplary design process on the process layer. Using BPMN, a process is modelled within a pool representing the process owner (Design Process Manager). Within the pool, there are one or more lanes representing the process participants (e.g., project manager). In the lanes, the participants' activities, e.g., Requirements elicitation for Systems Engineering, are placed and by this assigned to the participant. Not only activities can be placed within a lane, also events like Project launch as a start event or $M S$ Requirements fix as an intermediate event can be placed within a lane. A process always ends with an end event (not shown in Figure 2). Events and activities are connected by sequence flows (solid lines). Gateways (diamonds) can be used to control the process flow. They can be used, e.g., to split up the sequence flow and start parallel activities like presented in Figure 2 at the first gateway.

As introduced above, BPMN models can be used to represent strategic levels as well as operative levels of processes within companies. To support collaborative design teams, it is necessary to break down the activities in the processes to the operative level, where the team members interact. The example in Figure 2 shows interactions on a more abstract level using domains within the pools. On the operative level, each participant could be one of the team members if reasonable. In this way, critical process elements can be analysed in detail. The modelling approach on operative level can then be used to link methods and competencies to the activities as the description up to now is again only the representation of one layer, the process layer. The BPNM model is now extended by the view of the other two layers (methods \& tools and competencies \& qualification). Methods \& tools and competencies \& qualification are integrated into the processes by partial using modelling elements not defined in the BPMN. In a first expansion stage of the model, basically standard UML elements with custom shapes are used to represent methods and competencies as shown in Figure 2.

As mentioned above, methods can support on the operative level, thus, they are attached to design activities (boxes) based on the idea of basic activities as proposed by Franke et al. (2003). In the extended BPMN model, the methods are represented by clouds like Design methods, which is exemplarily pinned to the System design activity (see Figure 2). By adding the methods in the model, current method applications can be made transparent to all collaborators in the team. Furthermore, the linkage to method 
descriptions as proposed by Bavendiek et al. (2016b) could be implemented in another stage. The advantage of a direct linkage to the method description is the availability of a consistent information basis for all team members independent from where they work.

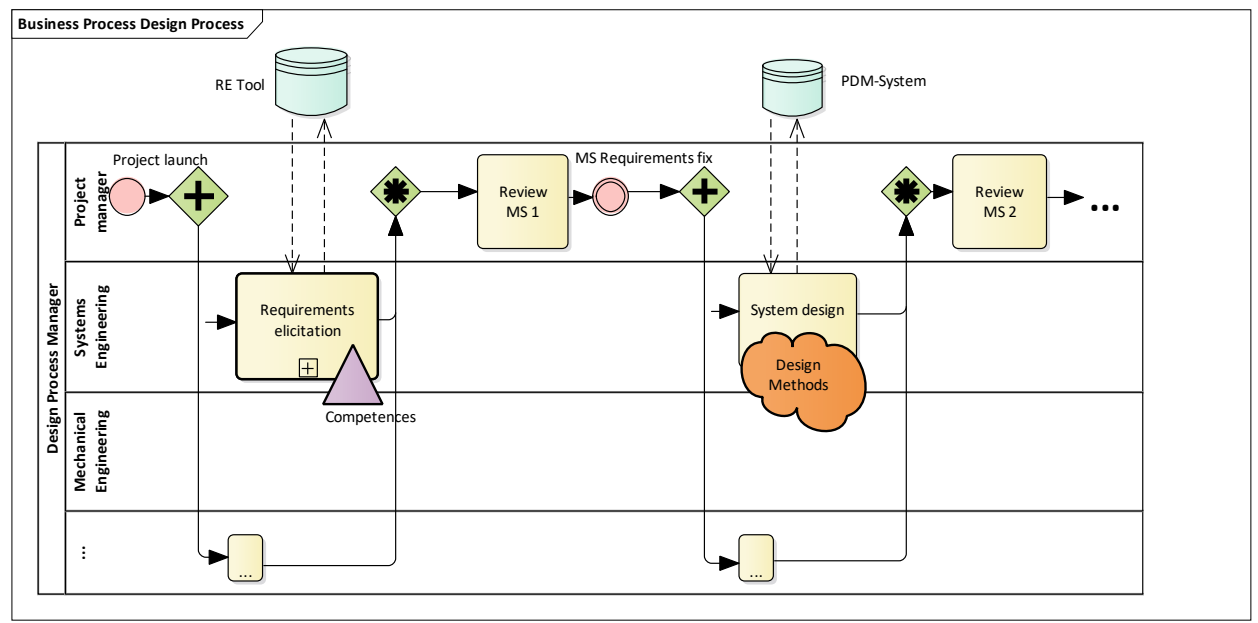

Figure 2. Example BPMN-Process diagram

Communication technologies are another element on the methods \& tools layer. To model these, standard BPMN-Data Stores (RE Tool and PDM-System in Figure 2) are used. There are some standard symbols like e-mails and data storage. The elements are utilized but extended by further information on the technologies and media intended to be applied and the information to be shared or transferred. The formal modelling approach defines the way of communication and avoids misunderstandings due to missing shared information.

The third layer, the competencies \& qualification, completes the modelling approach corresponding to the three layers of the PMC model. The idea of linking competencies to processes is based on previous work on approaches to assign competencies to processes (e.g., Soderquist et al., 2010; Kauffeld and Paulsen, 2018). Thus, required competencies for an activity are attached to the corresponding design activity. They are modelled with triangles like the Communication Competencies attached to the activity Requirements elicitation. To do so, a set of competencies especially needed in collaborative design will be used to assign more specified competencies to the (critical) design activities. In future work in the research project, this set of competencies will add up to a competency model as mentioned by, e.g., Sanchez and Levine (2009) or Campion et al. (2011) for collaborative design. Qualifications, though, will not be modelled directly in the BPMN model.

After introducing the used elements for modelling the three layers of the PMC model briefly, the usage of the model shall be clarified in the following. There are mainly two general aims for applying the modelling approach. The first one aims at the description of current processes in collaborations in order to identify hot spots, e.g., in terms of missing or redundant information. Based on this analysis, specific measures to structure the process more effectively by means of introducing or defining methods or tools can be derived. The second aim can be the definition of processes when introducing new technologies like cloud-based systems, industry 4.0 solutions or VR technologies, e.g., for meetings.

In the first application scenario, the modelling is done based on existing processes. These are extended later on to eliminate the identified hot spots. In the second scenario, the modelling is done from scratch although existing processes have to be kept in mind.

\section{Application}

The above-developed modelling approach was applied in a governmental funded research project at two of the industry partners. The example presented here comes from a medium-sized enterprise in the industrial sector of mechanical engineering. The main site is located in Germany. Further sites organised as subsidiary enterprises are located in India and China. The process considered in the following is a collaboration of the German and Indian site. 


\subsection{Exemplary process for a distributed development}

The process modelled with the presented modelling approach describes the current state in the GermanIndian collaboration within the development of an adapted product, mainly variant design (see Figure 3 ). The process was analysed, as it is, within a workshop with participants of the process from the industry partner (developer, sales man, quality manager and head of development). The BPMN model was generated afterwards and iterated with the process participants. The aim for modelling the existing process was to derive improvements for future projects. The focus lies on the process itself and on the assisting (communication) tools and technological systems. Competencies are not the primer focus, but are considered as well.

There are four participants involved in the contemplated process: sales, development in Germany, development extern (India) and the order centre. After having created the order from a customer request, the development and order centre decide on whether to accept or not accept the order. To do so, a checklist with certain evaluation criteria is used to make the decision. When accepting, the development takes the decision on where to design (and produce) each component. For those components to be designed in India, the German colleagues provide templates of the components as PDF drawings and specifications on the adapted design. The documents are uploaded to a cloud storage that automatically informs the design office in India about the new documents. Additionally, the PDF files are sent via email to the Indian colleagues together with the development order. An Indian colleague transfers the PDF drawing into a CAD model, which is checked into the external PDM system before starting the design process. The resulting design is handed over as a PDF drawing (via the cloud storage) to the development in Germany, where another colleague controls the matching of all components and finally checks the data into the PDM system (internal). With this step, the design is finished.

As already mentioned in the process description, most of the communication and coordination is done via the PDM systems. The communication with colleagues from the extern development is assisted by e-mail and a cloud storage as well. Defining the collaboration according to the collaboration characteristics of Gaul (2001), there is no data access, no compatibility of tools and a distribution of components, not of tasks. Thus, the main focus are communication and coordination as the collaboration on component level is not given. There are no methods applied involving the different sites so far. Each site provides own methods and tools for the (adaption) design.

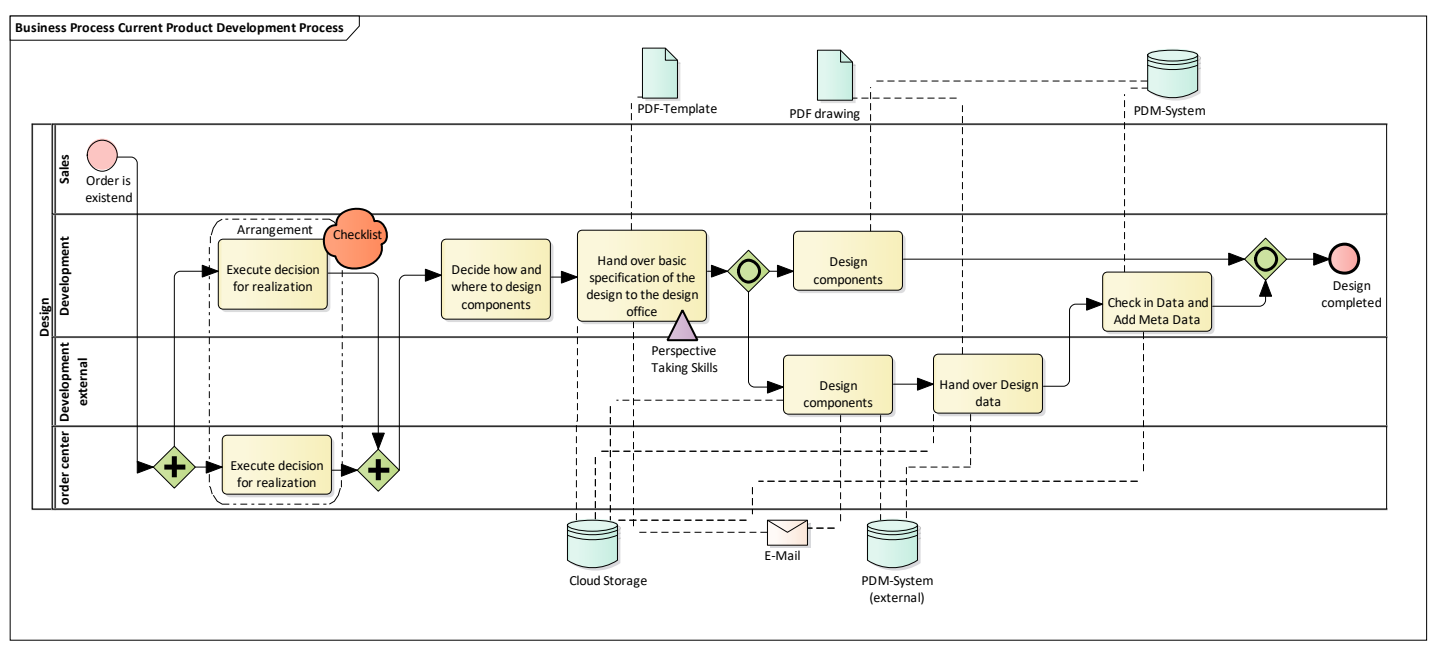

Figure 3. Current process of the distributed development of components at two sites

Relevant competencies for the collaboration can be found attached to the activity of handing over the development order and basic specifications. Here as an example, perspective taking skills are required to avoid problems. Perspective taking behaviours such as putting oneself in another person or treating different opinions equally were also found to be important in cross-culture virtual teams (Krumm et al., 2013). This means that adequate communication is needed to transport the work order. The communication to German colleagues requires different information (like CAD models, reference 
projects, etc.) than the communication to Indian colleagues, who have no access to data. The needed information (CAD models as PDF drawing specifications, etc.) has to be prepared and transferred separately. Furthermore, the person handing over the documents to India has to know English and an adequate way to phrase what he/she expects. The cited competencies are only examples for those attached to the BPMN model. As mentioned above, a complete competency model for distributed product development will be acquired using the before modelled distributed design scenarios.

\subsection{Discussion}

The discussion contains first some suggestions for improvements within the above-modelled process, which were identified with the industry partners; second the modelling approach is discussed in general presenting advantages, shortcomings, as well as recommendations for future applications. Though, the approach was not entirely evaluated regarding quality of the outcomes, validity, capability and usefulness within the industry application respectively among the practitioners.

One of the major problems in the existing process is the time-consuming step to create PDF drawings for the Indian colleagues and later on to generate CAD models from these drawings again. The standardisation of the PDM systems would be a preferable step towards a more compatible collaboration. This could save time and, thus, costs due to redundant work that is avoided when using the same CAD models. Even though first attempts were started to introduce the same PDM system, concerns came up especially from the Indian colleagues due to the safety of the data. This leads to the next aspect, the confidence in all partners in the collaboration. There are strict access authorisations at the Indian site whereas all designers in Germany have access to all models and data. So, the roles and access authorisation strategies are dissimilar at the two sites. If a common PDM system shall be used for both sites, the definition of rules and access strategies is a key aspect to establish a successful collaboration. Furthermore, it is planned to develop a database which contains information about which site and which departments possess which skills and knowledge on certain components or products. This information could be connected to the BPMN model as information on each process participant.

Considering the proposed modelling approach in general, the great advantage consists in the formalized modelling approach. This allows to analyse the model regarding different aspects automatically, like considering one method and identifying which activities are connected to the method. The same can be analysed for competencies: By analysing all connections to activities, it can be identified where the competency in question is required. Additionally, it can be identified which other elements are linked to an activity or to one participant (in one pool lane). Note that this advantage cannot be demonstrated in this contribution as we can only provide a graphical representation of the process and its linkages. As motivated in the beginning, the modelling approach allows a holistic consideration of collaborations from three different views, the process view as basis, the attached methods \& tools as well as qualification \& competencies view.

However, there are some shortcomings of the modelling approach. For instance, the linkage of communication tools and methods as it was proposed by Bavendiek et al. (2016a) cannot be represented, yet. The connection can only be considered by additional information added to the methods or communication tools. Furthermore, the linkage of methods and competencies (also proposed by Bavendiek et al., 2016a) is not represented in the current BPMN model. Again, the workaround of using additional information can be used. Alternatively, the linkage to another system like a method portal could be utilized to provide the information on the interrelation of methods and communication technologies or methods and competencies. Still, the identification of suitable methods \& tools for the individual process has to be assisted. In the presented application, this step was deduced by corresponding experts. The same applies for the competencies specified in the BPMN model. It has to be mentioned that there is no complete specific competency model for virtual or distributed team work available at present. The analysed processes as well as additional interviews will be used to build a corresponding competency model (see Paulsen et al., 2018). For the connection to the BPMN model it will be important to identify key aspects for virtual or distributed collaborations that allow the identification of corresponding activities in the processes to which the competencies can be linked. It is not intended to link competencies to any activity as not all of them require special competencies but traditional competencies like professional, social, methodological or self-competence (Kauffeld, 2006). 


\section{Conclusion}

The contribution presents actual challenges of collaborative design in today's product development. The PMC model introducing three layers (process, methods \& tools and competencies \& qualification) of collaborations is used to propose a modelling approach that allows the connection of the three layers in one model. BPMN elements standardized by the OMG and, thus, a formal modelling approach are the basis for this modelling approach. Originating from business process modelling, the process layer is the starting layer for the modelling approach for collaborative design. Within this layer, process participants, (design) activities and information or sequence flows are represented as main elements. Methods, tools and (communication) technologies are modelled and attached to the process layer to create a linkage between these layers. The connection to the third layer is built by linking competencies to design activities. The purpose of the presented modelling approach lies in representing existing processes that simplify the identification of hot spots and potential improvements through the holistic view on the process and its interrelations. Additionally, the approach can be used to define new processes, which are required, e.g., due to new technologies. First applications with industry partners promise suitable results for analysing the processes regarding hot spots and for proposing measures to eliminate these. The modelling approach shows some shortcomings, though. The connection of the methods \& tools layer to the competencies \& qualification layer is not represented directly. Nevertheless, the proposed approach offers diverse potentials for future analysis of collaborations.

\section{Acknowledgment}

This research and development project is funded by the German Federal Ministry of Education and Research (BMBF) within the Program "Innovations for Tomorrow's Production, Services, and Work" (02L15A250) and managed by the Project Management Agency Karlsruhe (PTKA). The author is responsible for the contents of this publication.

\section{References}

Albers, A., Reiss, N., Bursac, N. and Richter, T. (2016), "iPeM - Integrated Product Engineering Model in Context of Product Generation Engineering", Procedia CIRP, Vol. 50, pp. 100-105. https://doi.org/10.1016/j.procir.2016.04.168

Albers, A., Reiß, N., Bursac, N., Walter, B. and Gladysz, B. (2015), "InnoFox - Situationsspezifische Methodenempfehlung im Produktentstehungsprozess", Stuttgarter Symposium für Produktentwicklung 2015, Fraunhofer, Stuttgart.

Anderl, R., Lindemann, U., Thomson, B., Gaul, H.-D., Gierhardt, H. and Ott, T. (1999), "Investigation of distributed Product Design and Development Processes", Proceedings of the ICED $99 / 12^{\text {th }}$ International Conference on Engineering Design, Munich, Germany, August 24-26, 1999.

Arthur Technologies (2017), Discover team meetings in Virtual Reality. [online] Available at: http://arthur.digital/

Auffermann, C., Fisseler, B., Kehl, V., Kunzendorf, M. and Wolf, M. (2007), "Ganzheitliche Kompetenzentwicklung für die Arbeit in virtuellen Unternehmen mit dem 'virtuellen Qualifizierungscoach (VICO)'”, In: BMBF (Ed.), Gestaltung der Arbeit in virtuellen Unternehmen, Bonn, Berlin, pp. 50-59.

Badke-Schaub, P. and Frankenberger, E. (2004), Management kritischer Situationen: Produktentwicklung erfolgreich gestalten, Springer, Berlin. https://doi.org/10.1007/978-3-642-18702-5

Bavendiek, A.-K., Inkermann, D. and Vietor, T. (2016a), "Supporting collaborative design by digital tools Potentials and Challenges", Proceedings of the NordDesign 2016, The Design Society, Glasgow, pp. 248-257.

Bavendiek, A.-K., Inkermann, D. and Vietor, T. (2016b), "Teaching design methods with the interactive 'Methodos' portal", Proceedings of the DESIGN 2016 / 14 th International Design Conference, Dubrovnik, Croatia, May 16-19, 2016, The Design Society, Glasgow, pp. 2049-2058.

Bavendiek, A.-K., Inkermann, D. and Vietor, T. (2017), "Interrelations between processes, methods, and tools in collaborative design - A framework", Proceedings of the ICED'17 / $21^{\text {st }}$ International Conference on Engineering Design, Vol. 8, Vancouver, Canada, August 21-25, 2017, The Design Society, pp. 349-358.

Bavendiek, A.-K., Thiele, L., Meyer, P., Vietor, T., Kauffeld, S. and Fingscheidt, T. (2015), "Meetings in the product development process: Appling design methods to improve team interaction and meeting outcomes", Proceedings of the ICED'15 / $20^{\text {th }}$ International Conference on Engineering Design, Milano, Italy, July 2731, 2015, The Design Society, Glasgow, pp. 319-328. 
Campion, M.A., Fink, A.A., Ruggeberg, B.J., Carr, L., Phillips, G.M. and Odman, R.B. (2011), "Doing Competencies well: Best Practices in Competency Modeling”, Personnel Psychology, Vol. 64 No. 1, pp. 225262. https://doi.org/10.1111/j.1744-6570.2010.01207.x

Cross, N. (2007). Engineering design methods: Strategies for product design, Wiley, Chichester.

Eckert, C.M., Wynn, D.C., Maier, J.F., Albers, A., Bursac, N. et al. (2017), "On the integration of product and process models in engineering design", Design Science, Vol. 3, pp. e3. https://doi.org/10.1017/dsj.2017.2

Ferguson, D.F. and Stockton, M. (2006), "Enterprise Business Process Management - Architecture, Technology and Standards", In: Dustdar, S., Fiadeiro, J.L. and Sheth, A.P. (Eds.), Business Process Management, Springer, Berlin, Heidelberg, pp. 1-15. https://doi.org/10.1007/11841760_1

Franke, H.-J., Löffler, S. and Deimel, M. (2003), "The Database "Methodos" Assists an Effective Application of Design Methods", Proceedings of the ICED'03 / 14th International Conference on Engineering Design, Stockholm, August 19-21, 2003, The Design Society, Glasgow.

Gaul, H.-D. (2001), Verteilte Produktentwicklung. Perspektiven und Modell zur Optimierung, PhD thesis, TU München.

Gero, J.S. and Kannengiesser, U. (2004), “The situated function-behaviour-structure framework", Design Studies, Vol. 25 No. 4, pp. 373-391. https://doi.org/10.1016/j.destud.2003.10.010

Girard, P. and Merlo, C. (2003), "GRAI Engineering Method for Design Performance Improvement”, Proceedings of the ICED'03 / 14 th International Conference on Engineering Design, Stockholm, August 19-21, 2003, The Design Society, Glasgow.

Grieb, J.C. (2008), Auswahl von Werkzeugen und Methoden für verteilte Produktentwicklungsprozesse, $\mathrm{PhD}$ thesis, TU München.

Grieb, J.C. and Lindemann, U. (2005), "Design communication in industry: A survey analysis", Proceedings of the ICED'05 / $15^{\text {th }}$ International Conference on Engineering Design, Melbourne, Australia, August 15-18, 2005, The Design Society, Glasgow, pp. 586-578.

Kauffeld, S. (2006), "Self-directed work groups and team competence", Journal of Occupational and Organizational Psychology, Vol. 79 No. 1, pp. 1-21. https://doi.org/10.1348/096317905X53237

Kauffeld, S. and Paulsen, H. (2018), Kompetenzmanagement in kleinen und mittleren Unternehmen: Kompetenzen beschreiben, messen, entwicklen und nutzen, Kohlhammer, Stuttgart.

Kortsch, T., Paulsen, H. and Kauffeld, S. (2018), "Unterstützungskultur trifft auf digitale Lösungen: Kompetenzentwicklung mit dem KOMPETENZ-NAVI optimieren”, In: Kauffeld, S. and Paulsen, H. (Eds.), Kompetenzmanagement in kleinen und mittelständischen Unternehmen, Springer, Berlin, Heidelberg, pp. 181193. https://doi.org/10.1007/978-3-662-54830-1_11

Krumm, S., Kanthak, J., Hartmann, K. and Hertel, G. (2016), "What does it take to be a virtual team player?: The knowledge, skills, abilities, and other characteristics required in virtual teams", Human Performance, Vol. 29 No. 2, pp. 123-142. https://doi.org/10.1080/08959285.2016.1154061

Krumm, S., Terwiel, K. and Hertel, G. (2013), "Challenges in Norm Formation and Adherence: The Knowledge, Skills, and Ability Requirements of Virtual and Traditional Cross-Cultural Teams", Journal of Personnel Psychology, Vol. 12 No. 1, pp. 33-44. https://doi.org/10.1027/1866-5888/a000077

Lindemann, U. (2009), Methodische Entwicklung technischer Produkte: Methoden flexibel und situationsgerecht anwenden, Springer, Berlin Heidelberg. https://doi.org/10.1007/978-3-642-01423-9

Mansfield, R.S. (1996), "Building competency models: Approaches for HR professionals", Human Resource Management, Vol. 35 No. 1, pp. 7-18. https://doi.org/10.1002/(SICI)1099-050X(199621)35:1<7::AIDHRM1>3.0.CO;2-2

Martinec, T. and Pavkovic, N. (2014), "Visualization of information traceability in product development", Proceedings of the DESIGN 2014 / $13^{\text {th }}$ International Design Conference, Dubrovnik, Croatia, May 19-22, 2014, The Design Society, Glasgow, pp. 1831-1842.

Martinec, T., Škec, S. and Štorga, M. (2017), "Exploring the decomposition of team design activity", Proceedings of the ICED'17 / $21^{\text {st }}$ International Conference on Engineering Design, Vol. 8, Vancouver, Canada, August 21-25, 2017, The Design Society, Glasgow, pp. 229-238.

Object Management Group (2011), Business Process Model and Notation ${ }^{\mathrm{TM}}$ (BPMN $\left.{ }^{\mathrm{TM}}\right)$ Version 2.0. [online] Available at: http://www.omg.org/spec/BPMN/2.0/

Paulsen, H., Straube, J., Handke, L., Inkermann, D., Bavendiek, A.-K. et al. (2018), "Kompetenzanforderungen in der verteilten Produktentwicklung", Bericht zum 64. Arbeitswissenschaftlichen Kongress, Frankfurt am Main Februar 21-23, 2018.

Pol, G., Merlo, C., Legardeur, J. and Jared, G. (2008), "Implementation of collaborative design processes into PLM systems”, International Journal Product Lifecycle Management, Vol. 3 No. 4, pp. $279-294$. https://doi.org/10.1504/IJPLM.2008.027006 
Robin, V., Rose, B. and Girard, P. (2007), "Modelling collaborative knowledge to support engineering design project manager", Computers in Industry, Vol. 58 No. 2, pp. 188-198. https://doi.org/10.1016/j.compind.2006.09.006

Rose, B., Robin, V. and Sperandio, S. (2009), "How to Answer to the Challenges of Competencies Management in Collaborative Product Design?", Proceedings of the $19^{\text {th }}$ CIRP Design Conference - Competitive Design, Cranfield University Press, pp. 17-23.

Sanchez, J.I. and Levine, E.L. (2009), "What is (or should be) the difference between competency modeling and traditional job analysis?", Human Resource Management Review, Vol. 19 No. 2, pp. 53-63. https://doi.org/10.1016/j.hrmr.2008.10.002

Schleidt, B. (2009), Kompetenzen für Ingenieure in der unternehmensübergreifenden virtuellen Produktentwicklung, $\mathrm{PhD}$ thesis, TU Kaiserslautern.

Schleidt, B. and Eigner, M. (2010), "Competency Management Approach for Cross Enterprise Product Design", Proceedings of the DESIGN 2010 / $11^{\text {th }}$ International Design Conference, Dubrovnik, Croatia, May 17-20, 2010, The Design Society, Glasgow, pp. 11183-1188.

Schulze, J. and Krumm, S. (2017), "The "virtual team player': A review and initial model of knowledge, skills, abilities, and other characteristics for virtual collaboration”, Organizational Psychology Review, Vol. 7 No. 1, pp. 66-95. https://doi.org/10.1177/2041386616675522

Schulze, J., Schultze, M., West, S.G. and Krumm, S. (2017), "The Knowledge, Skills, Abilities, and Other Characteristics Required for Face-to-Face Versus Computer-Mediated Communication", Journal of Business and Psychology, Vol. 32 No. 3, pp. 283-300. https://doi.org/10.1007/s10869-016-9465-6

Shin, Y. (2004), “A Person-Environment Fit Model for Virtual Organizations”, Journal of Management, Vol. 30 No. 5, pp. 725-743. https://doi.org/10.1016/j.jm.2004.03.002

Soderquist, E. K., Papalexandris, A., Ioannou, G. and Prastacos, G. (2010), "From task-based to competencybased: A typology and process supporting a critical HRM transition”, Personnel Review, Vol. 39 No. 3, pp. 325-346. https://doi.org/10.1108/00483481011030520

SPP GmbH (2004), innovations-wissen.de. [online] Available at: http://www.innovationswissen.de/index.php?id=15

Stempfle, J. and Badke-Schaub, P. (2002), "Thinking in design teams - an analysis of team communication", Design Studies, Vol. 23 No. 5, pp. 473-496. https://doi.org/10.1016/S0142-694X(02)00004-2

Talas, Y., Gzara, L., Le Dain, M.-A., Merminod, V. and Frank, A.G. (2017), "Which are the limitations of ICT tools for collaborative design with suppliers?", Proceedings of the ICED'17 / $21^{\text {st }}$ International Conference on Engineering Design, Vol. 8, Vancouver, Canada, August 21-25, 2017, The Design Society, pp. 289-298.

TIM, Lehrstuhl für Betriebswirtschaftslehre mit Schwerpunkt Technologie- und Innovationsmanagement (2013), WiPro: Innovativ mit Methode. [online] Available at: http://www.innovationsmethoden.info/methodenliste

Törlind, P. and Larsson, A. (2002), "Support for Informal Communication in Distributed Engineering Design Teams", Annals of 2002 International CIRP Design Seminar, Hong-Kong, May 16-18, 2002.

Verein Deutscher Ingenieure (2004), Entwicklungsmethodik für mechatronische Systeme, Beuth, Berlin.

Wallace, K., Clegg, C. and Keane, A. (2001), "Visions for Engineering Design: A multidisciplinary perspective", Proceedings of the ICED'01 / $13^{\text {th }}$ International Conference on Engineering Design, Glasgow, UK, August 2123, 2001, pp. 107-114.

Wohed, P., van der Aalst, W.M.P., Dumas, M., ter Hofstede, A.H.M. and Russell, N. (2006), “On the Suitability of BPMN for Business Process Modelling”, In: Dustdar, S. Fiadeiro, J.L. and Sheth, A.P. (Eds.), Business Process Management, Springer, Berlin, Heidelberg, pp. 161-176. https://doi.org/10.1007/11841760_12

Wynn, D.C. and Clarkson, P.J. (2017), "Process models in design and development", Research in Engineering Design, Vol. 41 No. 2, pp. 161-202. https://doi.org/10.1007/s00163-017-0262-7

Yesilbas, L.G., Rose, B. and Lombard, M. (2006), "Specification of a repository to support collaborative knowledge exchanges in IPPOP project", Computers in Industry, Vol. 57 No. 8-9, pp. 690-710. https://doi.org/10.1016/j.compind.2006.04.014

Zanker, W. (1999), Situative Anpassung und Neukombination von Entwicklungsmethoden, PhD thesis, TU München.

Zier, S. and Birkhofer, H. (2013), "Investigating elementary design methods", Proceedings of the ICED'13/19th International Conference on Engineering Design, Vol. 2, Seoul, Korea, August 19-22, 2013, The Design Society, Glasgow, pp. 123-132.

Ann-Kathrin Bavendiek, M. Sc.

Technische Universität Braunschweig, Institut für Konstruktionstechnik

Langer Kamp 8, 38106 Braunschweig, Germany

Email: a-k.bavendiek@tu-braunschweig.de 